University of Nebraska - Lincoln

DigitalCommons@University of Nebraska - Lincoln

Faculty Publications, Department of Psychology

Psychology, Department of

January 2003

\title{
The Etiology and Treatment of Nicotine Dependence: A Biopsychosocial Perspective
}

\author{
Lee M. Cohen \\ Texas Tech University \\ Dennis E. McChargue \\ University of Nebraska-Lincoln, dmcchargue2@unl.edu \\ Monica Cortez-Garland \\ Texas Tech University \\ Eric H. Prensky \\ Texas Tech University \\ Sadie Emery \\ Texas Tech University
}

Follow this and additional works at: https://digitalcommons.unl.edu/psychfacpub

Part of the Psychiatry and Psychology Commons

Cohen, Lee M.; McChargue, Dennis E.; Cortez-Garland, Monica; Prensky, Eric H.; and Emery, Sadie, "The Etiology and Treatment of Nicotine Dependence: A Biopsychosocial Perspective" (2003). Faculty Publications, Department of Psychology. 306.

https://digitalcommons.unl.edu/psychfacpub/306

This Article is brought to you for free and open access by the Psychology, Department of at DigitalCommons@University of Nebraska - Lincoln. It has been accepted for inclusion in Faculty Publications, Department of Psychology by an authorized administrator of DigitalCommons@University of Nebraska - Lincoln. 
Published in:

The Health Psychology Handbook: Practical Issues for the Behavioral Medicine Specialist, Lee M. Cohen, Dennis E. McChargue, and Frank L. Collins, Jr., editors, Thousand Oaks, CA: SAGE Publications, 2003. Pages 101-124.

\section{5}

Author affiliations for this article:

Lee M. Cohen, Texas Tech University

Dennis E. McChargue, University of Illinois at Chicago \&

Edward Hines, Jr., Veterans Affairs Hospital

Monica Cortez-Garland, Texas Tech University

Eric H. Prensky, Texas Tech University

Sadie Emery, Texas Tech University 


\title{
The Etiology and Treatment of Nicotine Dependence
}

A Biopsychosocial Perspective

\author{
Lee M. Cohen, Dennis E. McChargue, \\ Monica Cortez-Garland, Eric H. Prensky, \\ AND SADIE EMERY
}

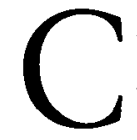

hronic use of tobacco-containing products, particularly cigarettes, remains one of the most avoidable causes of death and illness in the United States and claims the lives of more than 430,000 individuals each year (U.S. Department of Health and Human Services [DHHS], 1999). The number of tobacco-related deaths alone exceeds that of deaths due to AIDS, murders, other drugs, alcohol, car crashes, fires, and suicides combined (Centers for Disease Control and Prevention [CDC], 2002). Illnesses associated with tobacco use include, but are not limited to, laryngeal cancer, oral cancer, esophageal cancer, obstructive pulmonary disease, cardiovascular disease, intrauterine growth retardation, and low birth weight (DHHS, 1999). Evidence of significant health risks due to environmental tobacco smoke has also been documented. Adverse health risks caused by exposure to "secondhand" tobacco smoke include lung cancer, asthma, respiratory infections, and decreased pulmonary function (DHHS, 1999). Despite public health efforts to reduce tobacco use in the United States, adult prevalence rates have not changed significantly, and in some cases increases were observed during the 1990s (CDC, 2002). For example, the overall rate of adult cigarette smokers has decreased slightly from $25.0 \%$ to $23.3 \%$ across all age groups except that of 18 to 24-year-olds (CDC, 2002), whereas the use of smokeless (spit) tobacco and cigars has increased substantially (U.S. Department of Agriculture, 1997). To date, 65.5 million Americans continue to use tobacco products on a regular basis (CDC, 2002) and appear to be more difficult to treat than their counterparts of the 1970s and 1980s (Irvin \& Brandon, 2000). As such, tobacco use continues to represent an important health behavior that faces health care professionals. 


\section{DEFINITIONS AND DESCRIPTION OF NICOTINE DEPENDENCE}

The addictive process associated with tobacco use has been studied primarily with cigarette smoking, but there is a growing body of literature examining this process in spit tobacco (e.g., Hatsukami \& Severson, 1999; McChargue \& Collins, 1998) and cigar use (e.g., Henningfield, Fant, Radzius, \& Frost, 1999). The DSM-IVTR (Diagnostic and Statistical Manual of Mental Disorders, fourth edition, text revision [American Psychiatric Association, 2000]) classifies chronic tobacco use as a significant clinical impairment because of the psychological and neurobiological effects caused by nicotine-the presumed addictive ingredient found in tobacco products (Henningfield \& Heishman, 1995; Robinson \& Pritchard, 1992). As a clinical disorder, chronic tobacco use is classified as nicotine dependence when three of seven criteria are met within the same 12-month period. In particular, the four most prominent criteria of nicotine dependence are (a) developing a tolerance to nicotine, (b) experiencing nicotine withdrawal, (c) showing a persistent desire or unsuccessful efforts to quit or cut down the use of nicotine, and (d) continuing to use nicotine despite the development of physical or psychological problems that are likely to have been caused or exacerbated by tobacco products (American Psychiatric Association, 2000). Other general criteria for nicotine dependence include using larger amounts over a longer period of time; spending a great deal of time in activities necessary to obtain, use, or recover from nicotine; and experiencing impaired functioning (American Psychiatric Association, 2000).

\section{Tolerance}

Simply stated, tolerance is viewed as a diminished response or an adaptation to a given dose after repeated use (Balfour, 1991; Benowitz, 1990). Subjective, behavioral, and physiological adaptation has been shown following repeated exposure to nicotine (Balfour, 1991). For example, dizziness, nausea, and vomiting are associated with initial exposure to cigarette smoking; however, these symptoms disappear rapidly following habitual exposure (Benowitz, 1990). For the most part, tolerance to nicotine develops quickly, sometimes within 35 minutes of administration (Porchet, Benowitz, \& Sheiner, 1988). Once tolerance is developed, certain effects (e.g., dizziness) are more transient and dissipate rapidly following a short period of abstinence (Benowitz, 1990), whereas tolerance to most of the subjective and behavioral effects appears to be more long term (Perkins et al., 2001). Researchers have suggested that the rapid "re-sensitization" of the more transient effects, such as the "rush" one experiences from the first cigarette of the day, may partially explain why tobacco users tend to show stable use patterns without progressively increasing their dose amounts over time (Benowitz, 1990).

\section{Nicotine Withdrawal}

Nicotine withdrawal is defined as the manifestation of behavioral, subjective, physiologi$\mathrm{cal}$, and biochemical changes that occur when a person abruptly cuts down or quits using nicotine-containing products (Hughes, Higgins, \& Hatsukami, 1990). The withdrawal syndrome includes four or more of the following symptoms: (a) dysphoric or depressed mood; (b) insomnia; (c) irritability, frustration, or anger; (d) anxiety; (e) difficulty in concentrating; (f) restlessness; (g) decreased heart rate; and $(\mathrm{h}$ ) increased appetite or weight gain (American Psychiatric Association, 2000). In addition, these symptoms cause clinically significant distress or impairment in social, occupational, or other important areas of functioning, and the symptoms are not better accounted for by another mental disorder (American Psychiatric Association, 2000). 
Declining blood levels of nicotine have been associated with the onset of nicotine withdrawal; however, it is not clear whether the duration and severity of these symptoms are entirely attributable to the rate at which nicotine dissipates from a person's system. For example, nicotine reaches the brain within 10 to 19 seconds after smoking a cigarette, with brain levels of nicotine declining rapidly over 20 to 30 minutes (Benowitz, 1990). On the other hand, nicotine levels in the brain from spit tobacco tend to increase gradually, reaching their peak about 30 minutes after administration, and decline slowly over 2 hours or more (Benowitz, Porchet, \& Jacob, 1990). Despite the differing rates of nicotine absorption and depletion observed across these two modes of administration, spit tobacco users consistently report similar experiences of withdrawal, both in terms of the types of symptoms experienced (Hatsukami, Gust, \& Keenan, 1987; McChargue \& Collins, 1998; McChargue, Collins, \& Cohen, 2002) and in terms of the level of severity (McChargue \& Collins, 1998). Thus, the severity of withdrawal symptoms may be dictated by a variety of individual differences, including tobacco use patterns (Killen, Fortmann, Newman, \& Varady, 1991), psychiatric comorbidities (Pomerleau, Marks, \& Pomerleau, 2000), and personality factors (Gilbert \& Gilbert, 1995; Madden et al., 1997).

In general, nicotine withdrawal occurs within 24 hours of abruptly reducing or quitting nicotine use, peaks between 48 hours (Hughes $\&$ Hatsukami, 1986) and 2 weeks (Shiffman, Paty, Guys, Kassel, \& Elash, 1995; West, Hajek, \& Belcher, 1989), and resolves after 1 month of abstinence (Hughes, 1992). However, similar to withdrawal severity, the duration of withdrawal patterns are also variable. For example, increases in hunger and weight gain are the most persistent symptoms, lasting as long as 6 months to 1 year (Hughes, 1992; Klesges et al., 1997). In addition, individuals who quit using nicotinecontaining products do not always report increased anxiety; however, in cases where anxiety is reported, it could be a function of brief lapses in their abstinence (e.g., periodically smoking one cigarette and then resuming abstinence [West \& Hajek, 1997]). Finally, depressive symptoms may persist beyond 1 month, especially among people who have experienced a major depressive episode in the past (Borrelli et al., 1996). In fact, data suggest that there is at least a $33 \%$ chance that people with a history of major depression will experience clinically significant levels of depressive symptoms at any time across the first 12 months of nicotine abstinence (Borrelli et al., 1996; Tsoh et al., 2000).

\section{Other Prominent Criteria for Nicotine Dependence}

Individuals who use nicotine-containing products also show signs and symptoms associated with the remaining criteria for nicotine dependence. Specifically, a strong and persistent desire to use tobacco maintains use patterns (Baker, Morse, \& Sherman, 1986; Tiffany, 1990) and contributes to difficulties in quitting (e.g., Tracy, 1994). Researchers question whether nicotine's ability to alter emotions (Baker et al., 1986; Carmody, 1990; Hall, Munoz, Reus, \& Sees, 1993) drives the motivation to use tobacco products or whether this increased motivation is more automatic (Tiffany, 1990) and independent from emotion (Robinson \& Berridge, 2000). Nevertheless, nicotine administration appears to create an intense motivation to use tobacco products that is difficult to break regardless of the mechanism that promotes the powerful desire to continue tobacco use.

Individuals who use tobacco also tend to experience extreme difficulty in quitting, and unsuccessful efforts usually are made before they are able to quit permanently. In fact, less than $5 \%$ of individuals who meet criteria for nicotine dependence are able to quit on their own (Fiore et al., 1990). This percentage increases to as high as $30 \%$ with assisted treatment for nicotine dependence (Fiore et al., 
2000). As stated earlier, fewer and fewer people have quit using tobacco products over the past decade (CDC, 2002) as compared with previous decades (Emmons, Kawachi, \& Barclay, 1997). The apparent plateau of cigarette smoking rates and the increase of spit tobacco and cigar use may suggest that today's tobacco users are more resistant to treatment efforts and may even possess underlying vulnerabilities that further establish tobacco use patterns (Gilbert \& Gilbert, 1995).

Finally, it is not uncommon for nicotinedependent individuals to continue to use tobacco products despite physical or psychological problems that may result from chronic nicotine exposure. Familiar examples include the patient with emphysema who continues to smoke while attached to an oxygen tank despite the inherent danger of doing so and the patient who smokes through a tracheotomy tube. Overall, there is anecdotal and empirical evidence suggesting that many patients with cardiovascular disease, chronic obstructive pulmonary disease, and/or cancerall of which are related to chronic tobacco use (DHHS, 1999)-continue their patterns of use (Gritz, Kristeller, \& Burns, 1993). Moreover, continued use is associated with a heightened mortality rate, whereas cessation post-disease diagnosis may improve prognoses (Gritz et al., 1993).

\section{A BIOPSYCHOSOCIAL LEARNING MODEL OF NICOTINE DEPENDENCE}

Nicotine dependence is a complex biopsychosocial phenomenon that originates from learning theory. The most parsimonious explanation is that nicotine's effects on neurobiological substrates interact with behavioral, emotional, and cognitive domains to create dependence. Evidence also suggests that chronic use patterns may produce secondary conditioning of the pharmacological effects on the brain (Rose \& Levin, 1991) and sensitization of some neurobiological systems (Robinson \& Berridge, 2000; Watkins, Koob, \& Markou, 2000). In general, tobacco use behaviors are maintained by nicotine's ability to enhance desirable effects (positive reinforcement) and to dispel undesirable effects (negative reinforcement). Over time, frequent and repeated use of tobacco products in specific situations, environments, and emotional states may automatically trigger tobacco use (secondary conditioning and sensitization) (Rose \& Levin, 1991; Shiffman, 1991). For example, a person who typically smokes while talking on the phone may light another cigarette when the phone rings without realizing that he or she already had a cigarette lit.

\section{Positive Reinforcement and Sensitization: A Story of Rewarding Properties}

The most widely studied neurobiological substrate associated with nicotine-related positive reinforcement is dopamine (Wise, 1998). The mesolimbic dopamine system has long been touted as the reward center of the brain that shapes goal-directed behavior (Olds \& Milner, 1954; Stein, Belluzzi, Ritter, \& Wise, 1974), including drug use behavior (Di Chiara, 1998; Koob \& Le Moal, 1997). Consistent with the reward hypothesis of dopamine, nicotine's preferential binding to nicotinic cholinergic receptors within the mesolimbic dopamine system (Clarke \& Pert, 1985) and nicotine's reliable activation of dopamine release within the same system (Pomerleau \& Pomerleau, 1984) suggest that nicotine produces powerful rewarding effects for people who use tobacco.

The rewarding effects of nicotine become more powerful over time due to the biphasic nature of nicotine's influence on dopamine release. During nicotine administration, the dopaminergic system becomes sensitized rather than habituated (e.g., tolerance) 
(Robinson \& Berridge, 2000; Watkins et al., 2000). In other words, dopamine release is enhanced, rather than diminished, from repeated exposure to nicotine. As levels of nicotine are depleted during abstinence, dopamine also shows neuroadaptative effects. Neuroadaptation reflects the progressive blunting of naturally occurring dopamine (Epping-Jordan, Watkins, Koob, \& Markou, 1998). The ever-growing disparity between sensitized dopamine release from nicotine administration and blunted naturally occurring dopamine release during nicotine abstinence is hypothesized to alter reward thresholds (Watkins et al., 2000), presumably making it very difficult for tobacco users to experience pleasure without the aid of nicotine.

Glutamate functioning also appears to play an important role in the positive reinforcement of nicotine via its symbiotic relationship with dopamine. As discussed earlier, dopaminergic functioning is regarded as the primary mechanism that accounts for the rewarding properties of nicotine. However, glutamate may actually strengthen nicotine's rewarding properties and permanently implant the effect of such reward into long-term memory. For instance, nicotine administration has been shown to increase glutamate release within the mesolimbic dopamine system (Garcia-Munoz, Patino, Young, \& Groves, 1996) as well as within hippocampal neurons associated with memory and learning (Radcliffe, Fisher, Gray, \& Dani, 1999). Given that glutamate is strongly linked to learning and memory (Goda \& Stevens, 1996), it has been hypothesized that the simultaneous activation of the hippocampal and dopaminergic systems solidifies the rewarding properties of nicotine (Mansvelder \& McGehee, 2000). Even after long periods of abstinence, the responsiveness of these systems to nicotine remains abnormal, suggesting that these neurotransmitters play a substantial role in the long-lasting, enduring changes associated with nicotine dependence (Pulvirenti \& Diana, 2001).
These long-lasting memories may help to explain the incongruent psychosocial findings related to the reward obtained from nicotine administration. A standard assumption has been that self-reported pleasure (e.g., positive affect or euphoria) acts as a substitute for the rewarding effects of nicotine. However, empirical evidence has not consistently produced data to support this assumption. If self-reported pleasure mimicked the neurobiological substrates, one would expect that pleasure would show sensitizing effects (i.e., more and more pleasure from repeated exposure) after nicotine administration and would show acute decreases in pleasure during nicotine abstinence. Although research shows the expected decrease in pleasure following nicotine abstinence (Hughes \& Hatsukami, 1986), euphoric effects during nicotine administration are minimal (Pomerleau \& Pomerleau, 1992) and may further diminish, rather than increase, with repeated exposure (Robinson \& Berridge, 2000). If pleasure diminishes with chronic nicotine use and is not linked with dopamine sensitization, memories about the pleasure-enhancing effects of nicotine may be sufficient for continued motivation to selfadminister nicotine.

As noted earlier, the rewarding effects of nicotine are long-lasting in a tobacco user's memory system. A plausible psychosocial mechanism that takes into account these embedded reward effects is positive smoking expectancies or the belief that smoking will lead to a positive outcome (e.g., relaxation). For decades, positive drug expectancies have been shown to reflect long-term drug use patterns (Vuchinich \& Tucker, 1988). In fact, a recent study showed that smoking outcome expectancies combine with one's tendency to experience negative affective states to predict smoking behavior over time (Cohen, McCarthy, Brown, \& Myers, 2002). These findings indicate that at least part of the commonly observed relationship between negative affect and smoking behavior can be explained by smoking expectancies. 


\section{Negative Reinforcement: A Story of Emotion Regulation}

When considering negative reinforcement associated with tobacco use disorders, nicotine administration is believed to have negative mood-alleviating properties via its manipulation of neurotransmitters such as serotonin (Carmody, 1990; Hall et al., 1993). Specifically, low levels of serotonin have been strongly associated with negative mood states (Maes \& Meltzer, 1995), and nicotine administration appears to increase levels of this neurotransmitter (Kenny, File, \& Neal, 2000). In fact, nicotine's ability to elevate serotonin levels may partially explain why people report that using nicotine-containing products alleviates negative affective states (Carmody, 1990; Hall et al., 1993). Consistent with the serotonin hypothesis of nicotine dependence, when one abstains from nicotine, medications that improve the efficiency of serotonin (e.g., serotonin reuptake inhibitors such as fluoxetine) prolong short-term abstinence (Niaura et al., 2002), particularly among smokers with high baseline levels of depression (Hitsman et al., 1999). Moreover, once people abstaining from nicotine are taken off of this type of medication, there is an increased likelihood that they will experience a major depressive episode (e.g., Borrelli et al., 1996). Hence, this depressive vulnerability during nicotine abstinence is particularly salient for depression-prone individuals.

Although many people report using tobacco products due to their negative mood-alleviating properties (Spielberger, Foreyt, Reheiser, \& Poston, 1998), psychosocial research investigating this hypothesis is mixed. It is clear that after short-term abstinence, nicotine administration will reverse any negative affective symptoms associated with the nicotine withdrawal syndrome. However, it remains unclear whether nicotine has the same effect on negative affect that is not associated with nicotine withdrawal. In some studies, administration of nicotine exhibits the expected mood-alleviating properties.
Specifically, older heavy smokers show dosedependent relief from stress and anxiety following nicotine administration (Gilbert, Robinson, Chamberlin, \& Spielberger, 1989), with higher doses of nicotine producing the greatest mood relief (Gilbert et al., 1989; Perkins et al., 1993). In addition, nicotine replacement therapy produces clinically significant reductions in symptoms of depression among nonsmokers suffering from major depression (Salin-Pascual, Rosas, JimenezGenchi, \& Rivera-Meza, 1996). Nevertheless, mood responses that are not shown to be related to nicotine withdrawal are highly variable. For instance, some evidence actually indicates that nicotine creates higher levels of anxiety and stress (Parrott, 1999; Piasecki \& Baker, 2000). Similarly, smoking in response to depression may increase, rather than decrease, symptoms of depression among smokers with a ruminative coping style (Richmond, Spring, Sommerfeld, \& McChargue, 2001).

Despite the apparent inconsistencies shown among studies examining negative mood relief from nicotine administration, the importance of the negative reinforcing properties of nicotine should not be minimized. In fact, if only a fraction of individuals achieve negative mood relief from the administration of nicotine, negative affect's role in the maintenance of tobacco use behaviors remains quite salient. For example, both baseline and post-quit negative affect predict relapse (Pomerleau, Adkins, \& Pertschuk, 1978; Swan, Ward, \& Jack, 1996; West et al., 1989). Furthermore, a large portion of tobacco users suffer from psychological problems that are associated with affective dysregulation (Breslau, 1995). Finally, personality traits that increase the likelihood of experiencing frequent and persistent bouts of negative affect predict tobacco use behaviors and relapse (Gilbert \& Gilbert, 1995). Although it remains unclear as to the properties of nicotine that negatively reinforce tobacco use, there is sufficient evidence to implicate the importance of negative reinforcement in nicotine dependence. 


\section{Classical Conditioning: A Story of Automatic Processes}

Classical conditioning occurs when nicotine administration (unconditioned stimulus) produces psychological and physiological states (unconditioned response) that are repeatedly paired with neutral stimuli (conditioned stimulus). In other words, chronic nicotine administration elicits many reinforcing properties that eventually become conditioned to environmental and psychological stimuli (Iwamoto, Fudala, Mundy, \& Williamson, 1987; Rose \& Levin, 1991). Over time, the repeated pairings between the once neutral stimuli and nicotine administration produce conditioned responses that initiate and maintain tobacco use behavior (Rose \& Levin, 1991). Conditioned responses from emotional and environmental cues reflect the activation of cognitive (Tiffany, 1990), emotional (Baker et al., 1986), and physiological (Robinson \& Berridge, 2000) domains. Exposure to such cues evokes strong tobacco use motivation or urges. Some researchers hypothesize that this increase in motivation reflects the desire to evoke a pleasant feeling or to take away unpleasant states (Baker et al., 1986), whereas others view this increased motivation as more automatic (Tiffany, 1990), that is, driven by sensitized neurobiological systems (Robinson \& Berridge, 2000).

\section{OTHER IMPORTANT \\ FACTORS IN NICOTINE DEPENDENCE RESEARCH}

\section{Genetics}

The development of nicotine dependence cannot result entirely from random interactions between neurobiological and psychosocial factors. It has been suggested that individuals who use tobacco and become nicotine dependent may be different from individuals who do not use tobacco because of biologically based predispositions that produce qualitatively different reinforcement from nicotine administration (Pomerleau \& Kardia, 1999). Evidence supporting the notion that genetic factors dictate who is likely to become nicotine dependent comes from a variety of sources. For example, twin studies have shown greater concordance rates in monozygotic twins than in dizygotic twins, with heritability estimates of $53 \%$ for tobacco use (see review by Hughes, 1986). In addition, certain individuals may be more sensitive to nicotinic properties than are others. A selective sensitivity to nicotine is hypothesized to produce more rapid tolerance and more extensive self-administration patterns (Pomerleau, 1995). As such, genetic factors may help to explain why certain subgroups of smokers become more dependent at earlier ages (e.g., Madden et al., 1999) and have extreme difficulties in quitting (e.g., Lerman et al., 1999).

\section{Gender and Ethnicity}

Rates of nicotine dependence appear to differ across gender and ethnic groups. In addition, the proportions of men and women who use tobacco products vary greatly in some countries, such as Japan and Greece, but not in others, such as the United States and the United Kingdom (Grunberg, Winders, \& Wewers, 1991). Thus, it may be that tobacco use is reinforced differently for women in countries where as many women use tobacco products as do men. In addition, certain minority populations (e.g., African Americans) within the United States report higher rates of tobacco use than do Caucasians (CDC, 1999), and women and minorities appear to be less successful at quitting (Piper, Fox, Welsch, Fiore, \& Baker, 2001). Therefore, these individuals are at greater risk for contracting smoking-related illnesses, making it very important to consider how gender and ethnicity influence the recruitment, retention, and treatment of nicotinedependent individuals (Piper et al., 2001). 
More is known about the etiology and treatment of nicotine dependence for women than for different ethnic groups. The scarcity of research on minorities that use tobacco products has led many researchers and practitioners to examine nicotine dependence among minority populations. Contemporary knowledge regarding what motivates U.S. women to use tobacco products, particularly cigarettes, has focused on two primary issues: (a) affect regulation and (b) weight control. In general, women are more affectively vulnerable than men, and it is believed that this vulnerability is well suited for nicotine's mood-alleviating effects. As such, women may receive greater mood regulatory benefits from smoking than do men, and this is believed to partially explain why women have more difficulty in quitting (Piper et al., 2001). In addition, women frequently express concern about gaining weight after they quit smoking (Klesges \& Klesges, 1988). This concern is not surprising given that individuals who are abstinent for 1 year will gain an average of 13 pounds (Klesges et al., 1997).

\section{Comorbid Personality and Psychopathology}

The influence of personality on tobacco use is based on the belief that traits predispose people to frequent and persistent aversive mood states (Cloninger, 1987; Tellegen, 1985; Tomkins \& McCarter, 1964). As such, many theorize that chronic exposure to mood dysregulation provides ample opportunity for people to learn that tobacco products are an efficient source of relief from these problematic affective states. Traits that are associated with compromised affective systems and tobacco use behavior include sensation seeking, neuroticism, extroversion, and psychoticism (Gilbert \& Gilbert, 1995; Spielberger \& Jacobs, 1982).

Contemporary research has identified an overwhelming proportion of patients with psychiatric mood, anxiety, and psychotic problems as possessing high levels of comorbid nicotine dependence (Hughes, Hatsukami, Mitchell, \& Dahlgren, 1986). Comorbid psychopathology represents an important issue to address in nicotine dependence research because these individuals report excessive dependence levels and have extreme difficulty in quitting (Hughes et al., 1986; McChargue, Gulliver, \& Hitsman, 2002a, 2002b). Moreover, psychiatric smokers are at a heightened risk of smoking and psychiatric-related health problems as compared with nonsmoking psychiatric patients and nonpsychiatric smokers (Jeste, Gladsjo, Lindamer, \& Lacro, 1996; Linkins \& Comstock, 1990). Prevalence rates of smoking among this population range from $31 \%$ to $90 \%$, depending on the psychiatric disorder (Beckham et al., 1997; de Leon et al., 1995; Hughes et al., 1986).

It has been hypothesized that chronic tobacco use observed among individuals with psychopathological problems reflects selfmedicating behaviors. According to the selfmedication hypothesis, psychiatric patients smoke in part because nicotine helps to regulate their symptomatology (Gilbert \& Gilbert, 1995). For example, patients with major depression may smoke to improve depressed mood states (Hall et al., 1993). Similarly, patients with schizophrenia may find that smoking helps to reduce negative symptoms such as anhedonia, apathy, blunted affect, and emotional withdrawal (McChargue et al., 2002a, 2002b). Finally, patients with posttraumatic stress disorder and other anxiety disorders may smoke to cope with emotional and physiological distress (Beckham et al., 1997).

This self-medication process transforms tobacco use into an extremely rewarding behavior for psychiatric individuals as compared with nonpsychiatric cohorts who report similar tobacco use patterns (Spring, Pingitore, \& McChargue, in press). As such, the goal of complete abstinence might not be initially possible for some psychiatric subgroups (e.g., individuals diagnosed with schizophrenia). These individuals may require 
a stepped care approach that focuses on reducing exposure to tobacco toxins until the individuals are able to stabilize lower rates of tobacco use and learn adequate coping skills (McChargue et al., 2002a, 2002b).

\section{ASSESSMENT AND TREATMENT}

As discussed earlier, nicotine dependence is maintained by many factors across diverse patient populations. Another issue that leads to difficulties in the treatment and assessment of nicotine dependence is the pervasive nature of tobacco use. Specifically, the widespread use of tobacco products forces clinical health psychologists to address issues related to this construct in a variety of settings and situations. Hence, clinicians are encouraged to be mindful of the settings or situations in which they deliver their interventions (Collins et al., 1999). Overall, it is recommended that a multidisciplinary approach to the assessment and treatment of nicotine dependence be used if long-term abstinence is to be achieved (Fagerström, 1991).

\section{Assessment of Nicotine Dependence}

The assessment of nicotine dependence may take many forms at differing levels of intensity within behavioral medicine settings. For example, the approach to assessments of nicotine dependence in an emergency room is likely to differ from the approach to assessments used in outpatient settings. Therefore, the assessment should be tailored to the specific setting. Prior to beginning an assessment, the clinician should consider the purpose for the assessment, the environment where the assessment will take place, and the form of intervention conducive to the setting.

\section{Pretreatment Assessments}

To provide adequate treatment, it is essential that the clinician conduct the most comprehensive evaluation possible. The evaluation should include the assessment of physiological, psychological, and social factors that appear to influence the patient's tobacco use patterns (Ockene, Kristeller, \& Donnelly, 1999). Pertinent information may be acquired via a clinical interview, self-report measures, a chart review, and corroboration from behavioral medicine staff. Ockene and colleagues (1999) noted that, at the very least, an assessment of nicotine dependence starts with a clinical interview. During this interview, physiological assessment questions should include past quit attempts, withdrawal symptoms experienced during past quit attempts, and the patient's perceived addiction to nicotine. Questions within the social domain should include the number of friends, family members, and coworkers who use tobacco products; the expected amount of social support or nonsupport; and the degree to which the patient can be assertive at rebuffing pressure from others to smoke (Ockene et al., 1999) . Included within the psychological assessment should be questions related to emotional problems (e.g., stress, depression), behavioral indexes (e.g., extent to which person will go to have a cigarette), and cognitive factors (e.g., self-efficacy beliefs about quitting [Ockene et al., 1999]). Ockene and colleagues (1999) also noted that gathering information about a patient's smoking history, as well as having the patient self-monitor his or her smoking behavior, can provide useful data that may aid in treatment specificity. Finally, health factors that may be a consequence of chronic use patterns should also be assessed, and patients who present with physical complaints (e.g., shortness of breath) should be referred to a physician (Ockene et al., 1999).

Pretreatment assessment can be as brief as a 10 -minute clinical interview or as long as a $2 \frac{1}{2}-$ hour structured assessment. Again, the setting and purpose of the assessment should dictate the type of assessment administered. For a relatively brief assessment or for information that will be incorporated within a larger assessment, 
there are a variety of standardized self-report measures that can be used to assess level of dependence, self-efficacy, readiness to quit, general reasons for use, and perceptions of what tobacco products do for the person. For more comprehensive interviews, several structured and semistructured interviews are available, including the Diagnostic Interview Schedule (Malgady, Rogler, \& Tryon, 1992) and the Structured Clinical Interview for the DSM-IV Axis I Disorders-Clinician Version (First, Spitzer, Gibbon, \& Williams, 1997).

Most self-report measures have adequate psychometric properties and have been used with a variety of populations. Although a detailed description of all tobacco-related measures available is beyond the scope of this chapter, the following measures are recommended.

\section{The Fagerström Test of Nicotine} Dependence (Heatherton, Kozlowski, Frecker, \& Fagerström, 1991): This is a 6item, self-report questionnaire designed to assess various components of smoking behavior, including an estimate of daily intake, difficulty in refraining, and other aspects related to the pattern of intake.

2. The Smoking Self-Efficacy Questionnaire (Colletti, Supnick, \& Payne, 1985): This is a 17-item questionnaire designed to assess respondents' beliefs about their ability to control their urges to smoke in a variety of situations.

3. The Smoking Consequences Questionnaire (Brandon \& Baker, 1991): The Smoking Consequences Questionnaire (SCQ) is a 50item measure designed to assess expectations associated with cigarette smoking. It has four factors: negative consequences (e.g., health risks), positive reinforcement/sensory satisfaction (e.g., taste, relaxation), negative reinforcement/negative affect reduction (e.g., reduction of sadness and anxiety), and appetite/weight control. The SCQ-Adult (Copeland, Brandon, \& Quinn, 1995) is an extension of the SCQ for use with an older population of dependent smokers.
4. The Contemplation Ladder (Biener \& Abrams, 1991): This is a measure of readiness to consider tobacco cessation. It is designed to assess a tobacco user's position on a continuum ranging from having no thoughts of quitting to being engaged in action to change one's tobacco use. The ladder is consistent with Prochaska and DiClemente's (1983) model, which states that tobacco cessation is the culmination of an extended process of behavior change. The measure employs a picture of a ladder, where each rung has an associated number that the patient is instructed to circle representing where he or she is in thinking about quitting.

\section{Posttreatment Assessments}

Posttreatment assessment allows the clinician to measure and adjust treatment efforts as necessary. Issues that may arise include treatment compliance, sudden exacerbation of clinical disorders (e.g., major depression), severe tobacco withdrawal, intense and persistent urges to use nicotine, weight gain, brief smoking lapses, and abstinence status. Many of these issues can be assessed using clinical interviews. A supplementary self-report measure is the Minnesota Nicotine Withdrawal Scale (Hughes \& Hatsukami, 1986), which assesses withdrawal severity. This measure may be used repeatedly to assess withdrawal across time.

For purposes of assessing treatment compliance, lapsing, and abstinence status, the clinician may assess tobacco use daily, weekly, or at designated follow-up times. Self-reported lapses and relapses in isolation or combined with biochemical verification have been used. A detailed description of the utility of biochemical markers of tobacco and cessation as well as recommendations for their application in clinical practice is beyond the scope of this chapter. However, the Society for Research on Nicotine and Tobacco Subcommittee on Biochemical Verification (2002) recently published an overview of this subject. In general, the committee noted that there are currently three 
biomarkers used to assess whether a person has been abstinent from nicotine: thiocyanate (SCN), cotinine, and expired carbon monoxide (CO). SCN and cotinine are metabolites of nicotine that indicate tobacco use over the past week, and $\mathrm{CO}$ (as obtained via expired air) indicates smoked tobacco use within the past 24 hours. The committee also noted that the standard indication of tobacco use has been cotinine levels above 15 nanograms per milliliter, carbon monoxide levels above 8 to 10 parts per million, and SCN levels of 78 to 84 micromoles per liter. (For a more in-depth review of biochemical verification recommendations, see Society for Research on Nicotine and Tobacco Subcommittee on Biochemical Verification, 2002.)

\section{Treatment of Nicotine Dependence}

The treatment of nicotine dependence should be viewed as a multidisciplinary stepped care approach. The stepped care approach starts with the assessment of the patient's motivation to quit and progresses to the implementation of brief interventions. For example, routine screening and brief counseling (less than 3 minutes) within emergency rooms increase long-term abstinence rates from $3 \%$ (usual care) to $8 \%$ to $11 \%$ (Bernstein $\&$ Becker, 2002). If the patient is unmotivated to quit, the clinician should incorporate motivational enhancing techniques within the brief intervention. Only after brief interventions are unsuccessful should the clinician refer the patient to more intensive treatments. As discussed in the next two subsections, all recommendations for brief and intensive interventions are consistent with the clinical practice guidelines for treating nicotine dependence (Fiore et al., 2000). It should be noted that both brief and intensive interventions recommend the inclusion of pharmacological treatment. However, pharmacological agents associated with treating nicotine dependence are discussed in a separate subsection.

\section{Brief Interventions}

Brief interventions are designed to be used in a variety of settings and should not take more than 3 to 10 minutes. Brief interventions include assessing tobacco use patterns and willingness to quit, advising the patient to make a quit attempt, assisting the patient in quitting, and scheduling follow-up sessions (Fiore et al., 2000). Unfortunately, not all tobacco-using patients are highly motivated to quit. In cases where the patient is not so motivated, it is recommended that the clinician use an empathetic therapeutic style that avoids arguments, increases self-efficacy, and encourages adaptive skills at quitting (Prochaska \& Goldstein, 1991). Confrontational and punitive styles may have the opposite effect by further decreasing the patient's motivation to quit (Miller \& Rollnick, 2002).

Brief assistance that has been shown to increase abstinence rates may be as simple as providing the patient with self-help material combined with recommending approved pharmacological treatment (Killen, Fortmann, Newman, \& Varady, 1990). Other brief techniques include (a) helping to identify upcoming challenges, (b) processing helpful skills from prior quit attempts, (c) reducing alcohol consumption during the first month of abstinence, (d) encouraging others who use tobacco within the same household to quit as well, (e) providing social support within the clinical environment, and ( $f$ ) helping the patient to find another supportive environment (Fiore et al., 2000).

The first follow-up session should be scheduled approximately 1 week after the quit date, with the second scheduled 1 to 3 weeks later (Fiore et al., 2000). During the follow-up, the clinician should remain supportive, highlight successes (no matter how small), and encourage problem solving. The patient may have a tendency to overemphasize an aspect of the quit attempt that is linked to failure (Shiffman et al., 1996). If so, the clinician should try to reframe the perceived failure as a learning 
experience and reengage the patient in problem solving (Fiore et al., 2000).

\section{Intensive Treatments}

It is recommended that intensive treatments be offered to all tobacco users because, on average, such interventions are more effective than brief interventions (Fiore et al., 2000). This recommendation, however, might not be feasible. Thus, for each individual who wishes to quit, the clinician is encouraged to use a stepped care approach that starts brief and progressively increases in intensity. The reason for this is that, under certain circumstances, brief interventions can be more effective than intensive interventions (Smith et al., 2001), and brief interventions are more practical in a variety of settings (e.g., primary care facilities).

\section{Treatment Format for Intensive} Treatments. To qualify as an intensive treatment, there must be a minimum of four sessions lasting more than 10 minutes each (Fiore et al., 2000). If feasible, group sessions of 8 to 10 people are recommended over individual sessions because the group setting fosters social support (Ockene et al., 1999). Sessions should be scheduled on a weekly basis during the initial 4 weeks of treatment and then biweekly for the next 4 weeks (Ockene et al., 1999). Finally, posttreatment follow-ups should be scheduled 6 to 12 months after the quit date (Kozlowski, Henningfield, \& Brigham, 2001).

Treatment Components. Many of the psychosocial components used in tobacco cessation treatment packages are cognitive-behavioral in nature. The purpose of these components is to break the association between smoking and other life activities and to increase the patient's ability to cope during abstinence. As stated earlier, pharmacological therapies are highly recommended in conjunction with these psychosocial interventions.
Before a patient attempts to quit, the patient is encouraged to gather as much about his or her smoking habit as possible. The patient is asked to pay attention to specific triggers that he or she believes will challenge the attempt at quitting. Tobacco-related triggers include situations, emotions, thoughts, and places that evoke strong urges to use tobacco. Selfmonitoring smoking behavior prior to a quit attempt often will help the patient to identify tobacco-related triggers that are relevant to his or her life. However, it is not atypical for many other "unexpected" triggers to arise once the patient has achieved abstinence. Thus, it is important to continue monitoring triggers long after the quit date. It is also suggested that the clinician provide the patient with education regarding the withdrawal symptoms that he or she may experience as well as the addictive nature of tobacco because this information can aid the patient in understanding the process of addiction (Fiore et al., 2000; Kozlowski et al., 2001). For example, skills training focused on problem solving and symptom management are helpful (Fiore et al., 2000). In addition, there are several nonspecific treatment factors that the clinician should provide during treatment. These treatment factors include discussing and eliciting positive expectancies, being supportive and understanding, and providing a time line for the quit attempt (Fiore et al., 2000; Kozlowski et al., 2001).

Once the patient quits, he or she may experience a variety of nicotine withdrawal symptoms that undermine quit attempts. It is important for the clinician to assist the patient in coping with these symptoms, particularly during the first month of abstinence. The clinician should encourage the patient to use the skills he or she learned during the pre-quit sessions. For example, encouraging the use of relaxation techniques (e.g., removing oneself from stressful situations, deep breathing) provides an alternative means by which to cope with stressful situations and negative affect associated with tobacco withdrawal 
(Dziegielewski \& Eater, 2000; Hatsukami \& Lando, 1999). The use of accessible substitutes, such as chewing gum, may also help the patient to cope with withdrawal symptoms (Cohen, Britt, Collins, al'Absi, \& McChargue, 2001; Cohen, Britt, Collins, Stott, \& Carter, 1999; Cohen, Collins, \& Britt, 1997). In addition, encouraging the patient to avoid situations where tobacco use is likely to occur (e.g., bars, bowling alleys) as well as to engage in healthy alternative behaviors (e.g., exercise) may help to prolong abstinence (Dziegielewski \& Eater, 2000; Ockene et al., 1999).

Finally, working with the patient to develop the requisite skills to elicit social support from others outside of treatment is integral to successful tobacco cessation (Fiore et al., 2000). One type of social support outside of therapy that should be suggested is Nicotine Anonymous (NicA). These mutual-help groups provide social and emotional support for many sufferers of addictive disorders through personal sharing on a weekly basis (Lichtenstein, 1999). It has been suggested that NicA may be most effective for highly dependent smokers or those who also abuse another substance (e.g., alcohol). At the very least, patients who do not have a significant outside support system may need more frequent contact from a clinician to support them during their quit attempts (Ockene et al., 1999).

\section{Pharmacological Interventions}

According to the Clinical Practice Guidelines (Fiore et al., 2000), many first-line medications exist for the treatment of nicotine dependence, as do several second-line medications. First-line medications have been established as efficacious through clinical trials and have been approved by the Food and Drug Administration (FDA) for use with nicotine dependence. First-line medications include nicotine replacement products (e.g., gums, patches, nasal sprays, inhalers) and buproprion-SR (sustained release). With the exception of nicotine gum, these interventions have been shown to approximately double abstinence rates when compared with placebo treatments.

Second-line treatments have also been found to be efficacious, but the use of these medications is limited due to the lack of FDA approval as treatment for nicotine dependence as well as concerns about potential side effects. Second-line treatments include fluoxetine, clonidine, nortriptyline, and a combination of nicotine replacement therapies. Mention of second-line therapies is limited to this paragraph because such therapies are not viable treatment options at this time. Thus, this subsection limits further discussion of pharmacology to first-line treatments.

Nicotine Replacement Therapy. Nicotine replacement therapy (NRT) is intended to break the conditioning of nicotine with environmental cues by making nicotine intake independent of events in the environment (Glover \& Glover, 2001). Although NRT provides lower doses of nicotine than do other tobacco products, it can be used to decrease the severity of withdrawal symptoms by providing a slow consistent dose of nicotine through an alternate administration route (Jarvis \& Sutherland, 1998). NRT comes in many different forms, including gums, patches, nasal sprays, and inhalers.

Nicotine Polacrilex (gum) was the first NRT approved by the FDA (Jarvis $\&$ Sutherland, 1998). The absorption rate is fairly rapid, and peak nicotine levels are reached within 20 to 30 minutes (Hatsukami $\&$ Lando, 1999). Use is recommended for 3 months (Hatsukami \& Lando, 1999). Although nicotine gum can be used on an as-needed basis to control tobacco urges, a fixed schedule has been shown to be more effective in dealing with withdrawal symptoms (Ockene et al., 1999). Nicotine gum is dispensed in 2- or 4-milligram doses, with the 4-milligram dose recommended for heavily dependent smokers (Fiore et al., 2000). 
The nicotine patch has a passive delivery system. The absorption of nicotine is slower than with the gum (Jarvis \& Sutherland, 1998), resulting in peak levels of nicotine 4 to 9 hours after administration (Hatsumaki \& Lando, 1999). The patch is available in either 24-hour (Habitrol, Nicoderm, and Nicoderm CQ) or 16-hour doses (Nicotrol). Typically, 24-hour patches have 21 or 22 milligrams of nicotine, whereas patches designed for 16-hour use have 15 milligrams of nicotine (Hatsukami \& Lando, 1999; Ockene et al., 1999).

A nicotine nasal spray is available with a prescription (Fiore et al., 2000) and decreases craving within minutes of use due to rapid absorption rates (Hatsukami \& Lando, 1999; Jarvis \& Sutherland, 1998; Ockene et al., 1999). Treatment is typically 6 to 8 weeks but can be extended to 3 months in severe cases (Hatsukami \& Lando, 1999; Ockene et al., 1999). It is important to note that the nasal spray may be more effective in situations where instant relief from nicotine craving is a priority (Hurt et al., 1998).

Finally, the nicotine inhaler dispenses 10 milligrams of nicotine per inhaler cartridge (Eissenberg, Stitzer, \& Henningfield, 1999; Hatsukami \& Lando, 1999). A unique feature of the inhaler is that it provides oral and tactile reinforcement because it consists of a mouthpiece and a nicotine cartridge as well as nicotine (Hatsukami \& Lando, 1999; Ockene et al., 1999).

Non-nicotine Therapies. Buproprion is an antidepressant medication that has been shown to aid in the management of nicotine withdrawal symptoms (Johnston, Robinson, Adams, Glassman, \& Covey, 1999). Although the mechanism of buproprion is not completely clear (Johnston et al., 1999), it is presumed to block neural reuptake of dopamine and/or norepinephrine (Fiore et al., 2000). Buproprion remains the only non-nicotine medication used in tobacco cessation programs that is approved by the FDA (Fiore et al., 2000; Johnston et al., 1999).
If All Else Fails. . .

If all else fails, the clinician is advised to lower tobacco use behavior when abstinence appears to be initially unattainable (McChargue et al., 2002a, 2002b) and/or pharmacological therapies are not suitable (Ockene et al., 1999). Reducing tobacco use may be accomplished via nicotine fading. Nicotine fading involves switching to a brand with lower nicotine levels as well as gradually decreasing the quantity of tobacco used (Ockene et al., 1999). For example, once cigarette consumption has been decreased to 5 to 10 cigarettes per day and has been stabilized at this level, a quit date should be reestablished (Ockene et al., 1999).

\section{CONCLUSIONS}

Chronic use of tobacco products has been linked to a number of serious health problems that affect many people throughout the world. It appears that nicotine dependence develops via the interaction between neurobiological substrates and cognitive, behavioral, and emotional domains. Although there are a variety of factors that contribute to the development of nicotine dependence, once people are dependent, it is clear that they have extreme difficulty in quitting. For the most part, treatment of nicotine dependence takes a stepped care approach, which begins with brief interventions and progresses to more intensive interventions. The goal of this chapter was to increase knowledge about nicotine dependence and to provide guidance on intervention strategies for treating individuals with nicotine dependence. Given the pervasiveness of tobacco use disorders among various patient populations and the health consequences associated with these disorders, treatment of nicotine dependence is one area in which clinical health psychologists can have a positive impact on their patients' overall health status. 


\section{CASE STUDY}

This case study illustrates an intensive smoking treatment. The client, "Betty," was a 67-year-old Caucasian female who was referred by her primary care physician for individual smoking treatment. Betty presented with complaints of having "no control" over her smoking behavior but having a strong desire to quit smoking. She also reported that her health was "failing" and that her physician would not perform "a necessary medical procedure" unless she quit. Specifically, Betty noted that she suffered from numerous medical problems, including chronic bronchitis, asthma, and emphysema. Medical concerns had reduced her independence by causing her to rely on a motorized scooter for community mobility. Betty reported that she lived in an apartment by herself and noted that she had very little local social support. She did indicate, however, that she had several relatives who lived "out of state" with whom she talked via phone on a weekly basis.

During Betty's intake session, she was asked to exhale into a CO monitor and to complete the Fagerström Test of Nicotine Dependence. Results revealed a CO reading of 48 parts per million (indicating heavy smoking rates) and a test score of 9 (indicating a high level of nicotine dependence). In addition to these measures, a detailed account of her smoking history and quit attempts was obtained via clinical interview. In sum, Betty reported smoking her first cigarette at the age of 12 years and progressing to daily cigarette smoking by the age of 14 years. She noted that when she was smoking at her heaviest rate, she smoked two packs (40 cigarettes) per day, but she was currently smoking 25 cigarettes per day. Betty reported that she had tried unsuccessfully to quit smoking many times in her life, noting that she could recall four occasions when she made "serious attempts" to quit by using group smoking cessation programs, using nicotine replacement patches, and stopping "cold turkey." Betty made it clear to the therapist that she did not want to use nicotine replacement patches this time because she had "vivid disturbing dreams" the last time she had used them. She noted that her previous quit attempts resulted in temporary cessation, with her longest period of abstinence being a little more than $1 \frac{1}{2}$ years. She also noted, on a scale of 1 to 10 , that she had a strong desire to quit smoking (10/10), that it was very important that she quit smoking $(10 / 10)$, but that she was only somewhat confident in her ability to quit $(5 / 10)$.

Betty agreed to attend weekly sessions for the next 8 weeks. Betty and the therapist collaboratively planned to reduce her nicotine intake and to have her learn more about her smoking behavior (e.g., when she smoked, where she smoked, why she smoked) during the first 4 weeks of treatment. A quit date was set for Week 5, and during Weeks 6 to 8 it was decided that the focus of treatment would be on issues related to relapse prevention. Betty left the intake session with two "homework" assignments, namely (a) to attempt to reduce smoking intake by $10 \%$ during the week and (b) to keep a written record of her smoking behavior. Specifically, each time she was about to smoke a cigarette, Betty was asked to write down the time of day, any emotions she was feeling at the time, and the situational circumstances that occurred just prior to her smoking. 
Betty presented for her second session on time and indicated that she had reduced her smoking intake successfully and kept accurate records of her smoking behavior. She was eager to report that by the end of the week, she was able to reduce her smoking to 10 cigarettes per day (a far greater reduction than the agreed-on $10 \%$ ). She also noted that she wanted to smoke more frequently than she actually did; however, she "got sick" of writing down all of the requested information before each cigarette. She noted that tracking her smoking behavior allowed her to cut out many cigarettes that she did not "really need." She also indicated that in reducing her smoking intake, she learned that the "cravings" she had to smoke throughout the day would not "last forever" and in fact passed rather quickly, usually within 10 to 15 minutes. After praising Betty on the progress she had made during the past week, the therapist reviewed the "smoking record sheets" that Betty had completed in an attempt to identify commonalities in her smoking behavior. Examination of the smoking record sheets revealed that Betty smoked most often after eating meals and during times of perceived stress. In an attempt to aid Betty during these difficult times, urge control strategies were discussed.

One of the keys to success in smoking cessation is learning how to get through urges or cravings to smoke. Given that Betty had already learned how to get through some of her urges to smoke, the therapist enlisted Betty's help to get a sense of what worked for her during the past week. Betty noted that if she just waited long enough, her urge to smoke would go away (although she was quick to point out that the urges would return). Building on Betty's success, the therapist noted that delaying smoking might not work in all situations and taught Betty a number of other urge control strategies that might prove to be useful in situations where delaying smoking was too difficult. The therapist outlined five basic strategies that Betty could pull from her "tool box" when faced with difficult urges: (a) delaying smoking, (b) escaping from situations or events that may contribute to the urge, (c) avoiding situations where the temptation to smoke may be too great, (d) distracting herself by thinking about or doing other things that she enjoys doing, and (e) substituting something else for a cigarette such as sugarless gum, candy, or sunflower seeds. (All of these strategies can be remembered by the simple yet appropriate acronym of DEADS.) The therapist encouraged Betty to continue doing what worked for her the previous week and to try some of the other strategies that were taught when the urge to smoke surfaced. For "homework," Betty was again encouraged to reduce her smoking by $10 \%$. The therapist also encouraged Betty to pick a "smoking place" in her home where she usually did not smoke and did not engage in other activities such as talking on the phone, socializing, eating, watching television, and reading mail. It was suggested that she smoke only in this place, with the idea being that she would not associate smoking in this place with any other kind of activity. Also, it would mean that she would have to stop what she was doing so as to smoke a cigarette. 
During the third and fourth weeks of treatment, Betty was able to reduce her smoking to 4 cigarettes per day using the strategies discussed earlier. In anticipation of the Week 5 quit date, most of the fourth session was centered on preparing Betty for her quit attempt. She was instructed to have her final cigarette no later than before she went to bed on the night before she was to attend her fifth session. She was also encouraged to "seek out and destroy" all of the cigarettes that remained in her apartment that evening so as to be sure that there would not be any cigarettes readily available to her when she woke up the next morning. She was also educated about what types of withdrawal symptoms she might expect (e.g., depressed mood, irritability, anxiety) so that they would not catch her "off guard." In addition, detailed plans were made outlining how she would deal with her cravings to smoke so that she had a "plan of attack" if a craving surfaced. She was also encouraged to start thinking about how to reward herself once she quit.

During the fifth session, Betty was not as animated as she had been during the previous 4 weeks of treatment. She reported that she had not smoked a cigarette since before she went to bed the previous evening; however, she noted that she "really wanted one." The therapist reinforced Betty for all of her hard work and reminded her that her cravings would pass and that the intensity and frequency of the cravings would dissipate over time. The remainder of the session was spent discussing the health benefits that she could expect over the next several weeks (e.g., decrease in coughing and sinus congestion, increase in overall energy level). Finally, Betty was informed that she might "slip" and smoke a cigarette during the course of the next week. She was told that this is "normal" and that if it happens, she should look at it as just a "slip," not a "total relapse." She was encouraged to get back to being "smoke free" after the slip rather than to give herself permission to smoke as many cigarettes as she wanted and view her efforts as a failure.

Sessions 6 to 8 began with Betty exhaling into the CO monitor to show her that her $\mathrm{CO}$ levels were decreasing, thereby increasing the amount of oxygen that was circulating throughout her body. Her readings were 11,8 , and 7 , respectively. In addition, these sessions centered on ways in which Betty could prevent relapse. She had done exceptionally well and did not experience a slip during these 3 weeks. Betty and the therapist worked on anticipating difficult situations and planned ahead as to how she would cope with these situations if and when they arose. Betty was particularly concerned about what she would do in stressful situations that were bound to arise in the future. It was discussed how she could take a "time out," removing herself from the situation, taking deep breaths, and/or thinking of something fun she had recently done rather than smoking. At the end of Session 8 , Betty was commended for her hard work, given information about local support groups (in case she desired additional help), and was scheduled for three "booster sessions" 1,3 , and 6 months later. 
At 1-month follow-up, Betty reported that she had one slip during the holidays as she was caught off guard by her "emotions." She noted that she recognized what she was doing and immediately put out the cigarette and did not allow herself to smoke again. She noted that she repeatedly reminded herself of her hard work and told herself that she refused to "go back to Square One." She also noted that this slip was a "reality check" and reminded her that she should not get overconfident about her progress and that she had to continue to work on her addiction to nicotine. Betty admitted that she "would be lying" if she said she did not want a cigarette. But she added that the cravings were not occurring as often and that they were not as severe when they did occur. Betty was praised by the therapist and was encouraged to "keep her guard up." At the 3- and 6-month follow-ups, Betty reported that she had not slipped again and that her energy levels were up. At the 6-month follow-up, she reported that it looked as though her physician was considering performing the medical procedure she needed.

\section{REFERENCES}

American Psychiatric Association. (2000). Diagnostic and statistical manual of mental disorders (4th ed., text revision). Washington, DC: Author.

Baker, T. B., Morse, E., \& Sherman, J. E. (1986). The motivation to use drugs: A psychobiological analysis of urges. In C. Rivers (Ed.), The Nebraska Symposium on Motivation: Alcohol Use and Abuse (pp. 257-323). Lincoln: University of Nebraska Press.

Balfour, D. J. (1991). Neural mechanisms underlying nicotine dependence. Addiction, 89, 1419-1423.

Beckham, J. C., Kirby, A. C., Feldman, M. E., Hertzberg, M. A., Moore, S. D., Crawford, A. L., Davidson, J. R. T., \& Fairbank, J. A. (1997). Prevalence and correlates of heavy smoking in Vietnam veterans with chronic posttraumatic stress disorder. Addictive Behaviors, 22, 637-647.

Benowitz, N. L. (1990). Pharmacokinetic considerations in understanding nicotine dependence. In The biology of nicotine dependence (pp. 186-209). Chichester, UK: Wiley.

Benowitz, N. L., Porchet, H., \& Jacob, P., III. (1990). Pharmacokinetics, metabolism, and pharmacodynamics of nicotine. In S. Wonnacott, M. A. H. Russell, \& I. P. Stolerman (Eds.), Nicotine psychopharmacology: Molecular, cellular, and behavioural aspects (pp. 112-157). Oxford, UK: Oxford University Press.

Bernstein, S. L., \& Becker, B. M. (2002). Preventive care in the emergency department: Diagnosis and management of smoking and smoking-related illness in the emergency department-A systematic review. Academic Emergency Medicine, 9, 720-729.

Biener, L., \& Abrams, D. B. (1991). The contemplation ladder: Validation of a measure of readiness to consider smoking cessation. Health Psychology, 10, 360-365. 
Borrelli, B., Niaura, R., Keuthen, N., Goldstein, M., Depue, J., Murphy, C., \& Abrams, D. B. (1996). Development of major depressive disorder during smoking cessation treatment. Journal of Clinical Psychiatry, 57, 534-538.

Brandon, T. H., \& Baker, T. B. (1991). The Smoking Consequences Questionnaire: The subjective expected utility of smoking in college students. Psychological Assessment, 3, 484-491.

Breslau, N. (1995). Psychiatry comorbidity of smoking and nicotine dependence. Behavioral Genetics, 25, 95-101.

Carmody, T. P. (1990). Affect regulation, nicotine addiction, and smoking cessation. Journal of Psychoactive Drugs, 24, 111-122.

Centers for Disease Control and Prevention. (1999). Cigarette smoking among adults: United States, 1997. Morbidity and Mortality Weekly Report, 48, 993-996.

Centers for Disease Control and Prevention. (2002). Cigarette smoking among adults: United States, 2000. Morbidity and Mortality Weekly Report, 51, 642-645.

Clark, P. B., \& Pert, A. (1985). Autoradiographic evidence for nicotine receptors on nigrostriatal and mesolimbic dopaminergic neurons. Brain Research, 348, 355-358.

Cloninger, C. R. (1987). A systematic method for clinical description and classification of personality variates: A proposal. Archives of General Psychiatry, 44, 573-588.

Cohen, L. M., Britt, D. M., Collins, F. L., Jr., al'Absi, M., \& McChargue, D. E. (2001). Multimodal assessment of the effect of chewing gum on nicotine withdrawal. Addictive Behaviors, 26, 289-295.

Cohen, L. M., Britt, D. M., Collins, F. L., Jr., Stott, H. D., \& Carter, L. C. (1999). Chewing gum affects smoking topography. Experimental and Clinical Psychopharmacology, 7, 444-447.

Cohen, L. M., Collins, F. L., Jr., \& Britt, D. M. (1997). The effect of chewing gum on tobacco withdrawal. Addictive Behaviors, 22, 796-763.

Cohen, L. M., McCarthy, D. M., Brown, S. A., \& Myers, M. G. (2002). Negative affect combines with smoking outcome expectancies to predict smoking behavior. Psychology of Addictive Behaviors, 16, 91-97.

Colletti, G., Supnick, J. A., \& Payne, T. J. (1985). The Smoking Self-Efficacy Questionnaire (SSEQ): Preliminary scale development and validation. Behavioral Assessment, 7, 249-260.

Collins, F. L., Jr., Britt, D. M., Cohen, L. M., McChargue, D. E., Larson, M. E. M., Leftwich, M. J. T., \& Stott, H. D. (1999). Treating nicotine dependence. In L. VandeCreek \& T. L. Jackson (Eds.), Innovations in clinical practice: A source book (Vol. 17, pp. 135-151). Sarasota, FL: Professional Resources Press.

Copeland, A. L., Brandon, T. H., \& Quinn, E. P. (1995). The Smoking Consequences Questionnaire-Adult: Measurement of smoking outcome expectancies of experienced smokers. Psychological Assessment, 7, 484-494.

de Leon, J. D., Dadvand, M., Canuso, C., White, A. O., Stanilla, J. K., \& Simpson, G. M. (1995). Schizophrenia and smoking: An epidemiological survey in a state hospital. American Journal of Psychiatry, 152, 453-455.

Di Chiara, G. (1998). A motivational learning hypothesis of the role of mesolimbic dopamine in compulsive drug use. Journal of Psychopharmacology, 12, 54-67.

Dziegielewski, S. F., \& Eater, J. A. (2000). Smoking cessation: Increasing practice understanding and time-limited intervention strategy. Families in Society, 81, 246-255.

Eissenberg, T., Stitzer, M. L., \& Henningfield, J. E. (1999). Current issues in nicotine replacement. In D. F. Seidmean \& L. S. Covey (Eds.), Helping the hardcore smoker: A clinician's guide (pp. 137-158). Mahwah, NJ: Lawrence Erlbaum.

Emmons, K. M., Kawachi, I., \& Barclay, G. (1997). Tobacco control: A brief review of its history and prospects for the future. Hematological Oncology Clinics of North America, 2, 177-195. 
Epping-Jordan, M. P., Watkins, S. S., Koob, G. F., \& Markou, A. (1998). Dramatic decreases in brain reward function during nicotine withdrawal. Nature, 393, 6-79.

Fagerström, K. O. (1991). Towards better diagnoses and more individual treatment of tobacco dependence. British Journal of Addiction, 86, 543-547.

Fiore, M. C., Bailey, W. C., Cohen, S. J., Dorfman, S. F., Goldstein, M. G., Gritz, E. R., Heyman, R. B., Jaén, C. R., Kottke, T. E., Lando, H. A., Mecklenburg, R. E., Mullen, P. D., Nett, L. M., Robinson, L., Stitzer, M. L., Tommasello, A. C., Villejo, L., \& Wewers, M. E. (2000). Clinical practice guidelines: Treating tobacco use and dependence. Washington, DC: U.S. Department of Health and Human Services, Public Health Service.

Fiore, M. C., Novotny, T. E., Pierce, J. P., Giovino, G. A., Hatziandreu, E. J., Newcomb, P. A., Surawicz, T. S., \& Davis, R. M. (1990). Methods used to quit smoking in the United States. Journal of the American Medical Association, 263, 2760-2765.

First, M. B., Spitzer, R. L., Gibbon, M., \& Williams, J. B. W. (1997). Structured Clinical Interview for DSM-IV Axis I Disorders-Clinician's Version (SCIDCV). Washington, DC: American Psychiatric Association.

Garcia-Munoz, M., Patino, P., Young, S. J., \& Groves, P. M. (1996). Effects of nicotine on dopaminergic nigrostriatal axons requires stimulation of presynaptic glutamatergic receptors. Journal of Pharmacology of Experimental Therapeutics, $277,1685-1693$.

Gilbert, D. G., \& Gilbert, B. O. (1995). Personality, psychopathology, and nicotine response as mediators of the genetics of smoking. Behavior Genetics, 25(2), 133-147.

Gilbert, D. G., Robinson, J. H., Chamberlin, C. L., \& Spielberger, C. D. (1989). Effects of smoking/nicotine on anxiety, heart rate, and lateralization of EEG during a stressful movie. Psychophysiology, 26, 311-320.

Glover, E. D., \& Glover, P. N. (2001). Pharmacologic treatments for the nicotine dependent smoker. American Journal of Health Behavior, 25, 179-182.

Goda, Y., \& Stevens, C. F. (1996). Synaptic plasticity: The basis of particular types of learning. Current Biology, 6, 375-378.

Gritz, E. R., Kristeller, J. L., \& Burns, D. M. (1993). Treating nicotine addiction in high-risk groups and patients with medical co-morbidity. In C. T. Orleans \& J. S. Slade (Eds.), Nicotine addiction: Principles and management (pp. 279-309). New York: Oxford University Press.

Grunberg, N. E., Winders, S. E., \& Wewers, M. E. (1991). Gender differences in tobacco use. Health Psychology, 10, 143-153.

Hall, S. M., Munoz, F., Reus, V. I., \& Sees, K. L. (1993). Nicotine, negative affect, and depression. Journal of Consulting and Clinical Psychology, 61, 761-767.

Hatsukami, D. K., Gust, S. W., \& Keenan, R. M. (1987). Physiologic and subjective changes from smokeless tobacco withdrawal. Clinical Pharmacology Therapy, 41, 103-107.

Hatsukami, D. K., \& Lando, H. (1999). Smoking cessation. In P. J. Ott, R. E. Tarter, \& R. T. Ammerman (Eds.), Sourcebook on substance abuse: Etiology, epidemiology, assessment, and treatment (pp. 399-415). Boston: Allyn \& Bacon.

Hatsukami, D. K., \& Severson, H. H. (1999). Oral spit tobacco: Addiction, prevention, and treatment. Nicotine and Tobacco Research, 1, 21-44.

Heatherton, T. F., Kozlowski, L. T., Frecker, R. C., \& Fagerström, K. O. (1991). The Fagerström Test for Nicotine Dependence: A revision of the Fagerström Tolerance Questionnaire. British Journal of Addiction, 86, 1119-1127.

Henningfield, J. E., Fant, R. V., Radzius, A., \& Frost, S. (1999). Nicotine concentration, smoke $\mathrm{pH}$, and whole tobacco aqueous $\mathrm{pH}$ of some cigar brands and types popular in the United States. Nicotine and Tobacco Research, 1, 163-168. 
Henningfield, J. E., \& Heishman, S. J. (1995). The addictive role of nicotine in tobacco use. Psychopharmacology, 117, 11-13.

Hitsman, B., Pingitore, R., Spring, B., Mahableshwarkar, A., Mizes, J. S., Segraves, K. A., Kristeller, J. L., \& Xu, W. (1999). Antidepressant pharmacotherapy helps some cigarette smokers more than others. Journal of Consulting and Clinical Psychology, 67, 547-554.

Hughes, J. R. (1986). Genetics of smoking: A brief review. Behavior Therapy, 17, 335-345.

Hughes, J. R. (1992). Tobacco withdrawal in self-quitters. Journal of Consulting and Clinical Psychology, 60, 689-697.

Hughes, J. R., \& Hatsukami, D. (1986). Signs and symptoms of tobacco withdrawal. Archives of General Psychiatry, 43, 289-294.

Hughes, J. R., Hatsukami, D., Mitchell, J. E., \& Dahlgren, L. A. (1986). Prevalence of smoking among psychiatric outpatients. American Journal of Psychiatry, 143, 993-997.

Hughes, J. R., Higgins, S. T., \& Hatsukami, D. (1990). Effects of abstinence from tobacco: A critical review. In L. T. Kozlowski, H. Annis, H. D. Cappell, F. Glaser, M. Goodstadt, Y. Israel, H. Kalant, E. M. Sellers, \& J. Vingilis (Eds.), Research advances in alcohol and drug problems. (pp. 317-398). New York: Plenum.

Hurt, R. D., Offord, K. P., Croghan, I. T., Croghan, G. A., Gomez-Dahl, L. C., Wolter, T. D., Dale, L. C., \& Moyer, T. P. (1998). Temporal effects of nicotine nasal spray and gum on nicotine withdrawal symptoms. Psychopharmacology, 140, 98-104.

Irvin, J. E., \& Brandon, T. H. (2000). The increasing recalcitrance of smokers in clinical trials. Nicotine and Tobacco Research, 2, 79-84.

Iwamoto, E. T., Fudala, P. J., Mundy, W. R., \& Williamson, E. C. (1987). Nicotine actions in models of learning/memory and reward. In W. R. Martin, G. R. Van Loon, E. T. Iwamoto, \& L. Davis (Eds.), Tobacco smoking and nicotine: A neurobiological approach (pp. 101-111). New York: Plenum.

Jarvis, M., \& Sutherland, G. (1998). Tobacco smoking. In D. W. Johnston \& M. Johnston (Eds.), Comprehensive clinical psychology (pp. 645-674). New York: Elsevier Science.

Jeste, D. V., Gladsjo, J. A., Lindamer, L. A., \& Lacro, J. P. (1996). Medical comorbidity in schizophrenia. Schizophrenia Bulletin, 22, 413-430.

Johnston, A., Robinson, M. D., Adams, D. P., Glassman, A. H., \& Covey, L. S. (1999). Nonnicotine medications for smoking cessation. In D. F. Seidmean \& L. S. Covey (Eds.), Helping the hard-core smoker: A clinician's guide (pp. 159-173). Mahwah, NJ: Lawrence Erlbaum.

Kenny, P. J., File, S. E., \& Neal, M. J. (2000). Evidence for a complex influence of nicotinic acetylcholine receptors on hippocampal serotonin release. Journal of Neurochemistry, 75, 2409-2414.

Killen, J. D., Fortmann, S. P., Newman, B., \& Varady, A. (1990). Evaluation of a treatment approach combining nicotine gum with self-guided behavioral treatments for smoking relapse prevention. Journal of Consulting and Clinical Psychology, 58, 85-92.

Killen, J. D., Fortmann, S. P., Newman, B., \& Varady, A. (1991). Prospective study of factors influencing the development of craving associated with smoking cessation. Psychopharmacology, 105, 191-196.

Klesges, R. C., \& Klesges, L. M. (1988). Cigarette smoking as a dieting strategy in a university population. International Journal of Eating Disorders, 7, 413-419.

Klesges, R. C., Winders, S. E., Meyers, A. W., Eck, L. H., Ward, K. D., Hultquist, C. M., Ray, J. W., \& Shadish, W. R. (1997). How much weight gain occurs following smoking cessation? A comparison of weight gain using both continuous and point prevalence abstinence. Journal of Consulting and Clinical Psychology, 65, 286-291. 
Koob, G. F., \& Le Moal, M. (1997). Drug abuse: Hedonic homeostatic dysregulation. Science, 278, 52-58.

Kozlowski, L. T., Henningfield, J. E., \& Brigham, J. (2001). Cigarettes, nicotine, and health: A biobehavioral approach. Thousand Oaks, CA: Sage.

Lerman, C., Caporaso, N. E., Audrain, J., Main, D., Bowman, E. D., Lockshin, B., Boyd, N. R., \& Shields, P. G. (1999). Evidence suggesting the role of specific genetic factors in cigarette smoking. Health Psychology, 18, 19-34.

Lichtenstein, E. (1999). Nicotine Anonymous: Community resource and research implications. Psychology of Addictive Behaviors, 13, 60-68.

Linkins, R. W., \& Comstock, G. W. (1990). Depressed mood and development of cancer. American Journal of Epidemiology, 132, 962-972.

Madden, P. A. F., Bucholz, K. K., Dinwiddie, S. H., Slutske, W. S., Beirut, L. J., Statham, D. J., Dunne, M. P., Martin, N. G., \& Heath, A. C. (1997). Nicotine withdrawal in women. Addiction, 92, 889-902.

Madden, P. A. F., Heath, A. C., Pedersen, N. L., Kaprio, J., Koskenvuo, M. J., \& Martin, N. G. (1999). The genetics of smoking persistence in men and women: A multicultural study. Behavior Genetics, 29, 423-431.

Maes, M., \& Meltzer, H. Y. (1995). The serotonin hypothesis of major depression. In F. E. Bloom \& D. J. Kupfer (Eds.), Psychopharmacology: The fourth generation of progress (pp. 933-944). New York: Raven.

Malgady, R. G., Rogler, L. H., \& Tryon, W. W. (1992). Issues of validity in the Diagnostic Interview Schedule. Journal of Psychiatric Research, 26, 59-67.

Mansvelder, H. D., \& McGehee, D. S. (2000). Long-term potentiation of excitatory inputs to brain reward areas by nicotine. Neuron, 27, 349-357.

McChargue, D. E., \& Collins, F. L. (1998). Differentiating withdrawal patterns between smokers and smokeless tobacco users. Experimental and Clinical Psychopharmacology, 6, 205-208.

McChargue, D. E., Collins, F. L., \& Cohen, L. M. (2002). Effect of non-nicotinic moist snuff replacement and lobeline on withdrawal symptoms during 48-hour smokeless tobacco deprivation. Nicotine and Tobacco Research, 4, 195-200.

McChargue, D. E., Gulliver, S. B., \& Hitsman, B. (2002a). A reply to the commentaries on schizophrenia and smoking treatment: More research is needed. Addiction, 97, 785-793.

McChargue, D. E., Gulliver, S. B., \& Hitsman, B. (2002b). Would smokers with schizophrenia benefit from a more flexible approach to smoking treatment? Addiction, 97, 799-800.

Miller, W. R., \& Rollnick, S. (2002). Motivational interviewing: Preparing people for change. New York: Guilford.

Niaura, R., Spring, B., Borrelli, B., Hedeker, D., Goldstein, M. G., Keuthen, N., DePue, J., Kristeller, J., Ockene, J., Prochazka, A., Chiles, J. A., \& Abrams, D. B. (2002). Multicenter trial of fluoxetine as an adjunct to behavioral smoking cessation treatment. Journal of Consulting and Clinical Psychology, 70, 887-896.

Ockene, J. K., Kristeller, J. L., \& Donnelly, G. (1999). Tobacco. In M. Galanter \& H. D. Kleber (Eds.), The American Psychiatric Press textbook of substance abuse treatment (2nd ed., pp. 215-238). Washington, DC: American Psychiatric Association.

Olds, J., \& Milner, P. (1954). Positive reinforcement produced by electrical stimulation of septal area and other regions of rat brain. Journal of Comparative Physiological Psychology, 47, 419-427.

Parrott, A. C. (1999). Does cigarette smoking cause stress? American Psychologist, $54,817-820$.

Perkins, K. A., Gerlach, D., Broge, M., Sanders, M., Grobe, J., Fonte, C., Cherry, C., Wilson, A., \& Jacob, R. (2001). Quitting cigarette smoking produces minimal loss of chronic tolerance to nicotine. Psychopharmacology, 158, 7-17. 
Perkins, K. A., Grobe, J. E., Epstein, L. H., Caggiula, A., Stiller, R. L., \& Jacob, R. G. (1993). Chronic and acute tolerance to subjective effects of nicotine. Pharmacology Biochemistry and Behavior, 45, 375-381.

Piasecki, T. M., \& Baker, T. (2000). Does smoking amortize negative affect? American Psychologist, 55, 1156-1157.

Piper, M. E., Fox, B. J., Welsch, S. K., Fiore, M. C., \& Baker, T. B. (2001). Gender and racial/ethnic differences in tobacco-dependence treatment: A commentary and research recommendations. Nicotine and Tobacco Research, 3, 291-297.

Pomerleau, C. S., Marks, J. L., \& Pomerleau, O. F. (2000). Who gets what symptom? Effects of psychiatric cofactors and nicotine dependence on patterns of smoking withdrawal symptomatology. Nicotine and Tobacco Research, 2, 275-280.

Pomerleau, C. S., \& Pomerleau, O. F. (1992). Euphoriant effects of nicotine in smokers. Psychopharmacology, 108, 460-465.

Pomerleau, O. F. (1995). Individual differences in sensitivity to nicotine: Implications for genetic research on nicotine dependence. Behavior Genetics, 25, 161-177.

Pomerleau, O., Adkins, D., \& Pertschuk, M. (1978). Predictors of outcome and recidivism in smoking cessation treatment. Addictive Behaviors, 3, 65-70.

Pomerleau, O. F., \& Kardia, S. L. R. (1999). Introduction to the featured section: Genetic research on smoking. Health Psychology, 18, 3-6.

Pomerleau, O. F., \& Pomerleau, C. S. (1984). Neuroregulators and the reinforcement of smoking: Towards a biobehavioral explanation. Neuroscience and Biobehavioral Reviews, 8, 503-513.

Porchet, H. C., Benowitz, N. L., \& Sheiner, L. B. (1988). Pharmacodynamic model of tolerance: Application to nicotine. Journal of Pharmacology and Experimental Therapeutics, 244, 231-235.

Prochaska, J. O., \& DiClemente, C. C. (1983). Stages and processes of self-change of smoking: Toward an integrative model of change. Journal of Consulting and Clinical Psychology, 51, 390-395.

Prochaska, J., \& Goldstein, M. G. (1991). Process of smoking cessation. Implications for clinicians. Clinical Chest Medicine, 12, 727-735.

Pulvirenti, L., \& Diana, M. (2001). Drug dependence as a disorder of neural plasticity: Focus on dopamine and glutamate. Reviews in the Neurosciences, 12, 141-158.

Radcliffe, K. A., Fisher, J. L., Gray, R., \& Dani, J. A. (1999). Nicotinic modulation of glutamate and GABA synaptic transmission of hippocampal neurons. Annals of the New York Academy of Sciences, 868, 591-610.

Richmond, M., Spring, B., Sommerfeld, B. K., \& McChargue, D. E. (2001). Rumination and cigarette smoking: $\mathrm{A}$ bad combination for depressive outcomes? Journal of Consulting and Clinical Psychology, 69, 836-840.

Robinson, J. H., \& Pritchard, W. S. (1992). The role of nicotine in tobacco use. Psychopharmacology, 108, 397-407.

Robinson, T. E., \& Berridge, K. C. (2000). The psychology and neurobiology of addiction: An incentive-sensitization view. Addiction, 95, S91-S117.

Rose, J. E., \& Levin, E. D. (1991). Inter-relationships between conditioned and primary reinforcement in the maintenance of cigarette smoking. British Journal of Addiction, 86, 605-609.

Salin-Pascual, R. J., Rosas, M., Jimenez-Genchi, A., \& Rivera-Meza, B. L. (1996). Antidepressant effect of transdermal nicotine patches in nonsmoking patients with major depression. Journal of Clinical Psychiatry, 57, 387-389.

Shiffman, S. (1991). Refining models of dependence: Variations across persons and situations. British Journal of Addiction, 86, 611-615.

Shiffman, S., Hickcox, M., Paty, J. A., Guys, M., Kassel, J. D., \& Richards, T. J. (1996). Progression from a smoking lapse to relapse: Prediction from abstinence violation effects, nicotine dependence, and lapse characteristics. Journal of Consulting and Clinical Psychology, 64, 993-1002. 
Shiffman, S., Paty, J. A., Guys, M., Kassel, J. D., \& Elash, C. (1995). Nicotine withdrawal in chippers and regular smokers: Subjective and cognitive effects. Health Psychology, 14, 301-309.

Smith, S. S., Jorenby, D. E., Fiore, M. C., Anderson, J. E., Mielke, M. M., Beach, K. E., Piasecki, T. M., \& Baker, T. B. (2001). Strike while the iron is hot: Can stepped-care treatments resurrect relapsing smokers? Journal of Consulting and Clinical Psychology, 69, 429-439.

Society for Research on Nicotine and Tobacco Subcommittee on Biochemical Verification. (2002). Biochemical verification of tobacco use and cessation. Nicotine and Tobacco Research, 4, 149-159.

Spielberger, C. D., Foreyt, J. P., Reheiser, E. C., \& Poston, W. S. C. (1998). Motivational, emotional, and personality characteristics of smokeless tobacco users compared with cigarette smokers. Personality and Individual Differences, $25,821-832$.

Spielberger, C. D., \& Jacobs, G. A. (1982). Personality and smoking behavior. Journal of Personality Assessment, 46, 396-403.

Spring, B., Pingitore, G., \& McChargue, D. E. (in press). Reward value of cigarette smoking for comparably heavy smoking schizophrenic, depressed, and nonpatient smokers. American Journal of Psychiatry.

Stein, L., Belluzzi, J. D., Ritter, S., \& Wise, C. D. (1974). Self-stimulation reward pathways: Norepinephrine vs. dopamine. Journal of Psychiatric Research, 11, 115-124.

Swan, G. E., Ward, M. M., \& Jack, L. M. (1996). Abstinence effects as predictors of 28-day relapse in smokers. Addictive Behaviors, 21, 481-490.

Tellegen, A. (1985). Structures of mood and personality and their relevance to assessing anxiety, with an emphasis on self-report. In H. Tuma \& J. Maser (Eds.), Anxiety and anxiety disorders (pp. 681-706). Hillsdale, NJ: Lawrence Erlbaum.

Tiffany, S. T. (1990). A cognitive model of drug urges and drug-use behavior: Role of automatic and nonautomatic processes. Psychological Reviews, 97, 147-168.

Tomkins, S., \& McCarter, R. (1964). What and where are the primary affects? Some evidence for a theory. Perception and Motor Skills, 18, 119-156.

Tracy, J. I. (1994). Assessing the relationship between craving and relapse. Drug and Alcohol Review, 13, 71-77.

Tsoh, J. Y., Humfleet, G. L., Munoz, R. F., Reus, V. I., Hartz, D. T., \& Hall, S. M. (2000). Development of major depression after treatment for smoking cessation. American Journal of Psychiatry, 157, 368-374.

U.S. Department of Agriculture. (1997). Tobacco situation and outlook report (Series TBS, No. 239). Washington, DC: U.S. Department of Agriculture, Economic Research Service,

U.S. Department of Health and Human Services. (1999). Tobacco Use: United States, 1900-1999. Morbidity and Mortality Weekly Report, 48, 986-993.

Vuchinich, R. E., \& Tucker, J. A. (1988). Contributions from behavioral theories of choice to an analysis of alcohol abuse. Journal of Abnormal Psychology, 97, 181-195.

Watkins, S. S., Koob, G. F., \& Markou, A. (2000). Neural mechanisms underlying nicotine addiction: Acute positive reinforcement and withdrawal. Nicotine and Tobacco Research, 2, 19-37.

West, R., \& Hajek, P. (1997). What happens to anxiety levels on giving up smoking? American Journal of Psychiatry, 154, 1589-1592.

West, R., Hajek, P., \& Belcher, M. (1989). Severity of withdrawal symptoms as a predictor of outcome of an attempt to quit smoking. Psychological Medicine, $19,981-985$.

Wise, R. A. (1998). Drug-activation of brain reward pathways. Drug and Alcohol Dependence, 51, 13-22. 